\title{
PENGAMBILAN KEPUTUSAN SEBAGAI PEKERJA SEKS KOMERSIAL (PSK) PADA REMAJA LAKI-LAKI \\ (Studi Kasus Terhadap Remaja Laki-Laki Pelaku Prostitusi Di Kabupaten Pati)
}

\author{
DECISION MAKING TO BE COMMERSIAL SEKS WORKER AT BOYS \\ ADOLESCENT \\ (Case Study to Boys Adolescent Who Actor Prostitution at Pati Regency)
}

\author{
Siti Qorrotu Aini \\ Kantor Penelitian dan Pengembangan Kabupaten Pati \\ Email: ainiqurrotu85@gmail.com
}

Naskah Masuk: 23 September 2014 Naskah Revisi: 6 Oktober 2014 Naskah Diterima: 14 Oktober 2014

\begin{abstract}
The phenomenon of MSM (Men Sexual associated with man) is rapidly evolving, no longer limited to personal relationships but it is up to the commercial. Some adolescent boys had decided to become commercial sex workers. The purpose of this study was to describe the decision making process of teenage boys to become commercial sex workers. The research method is qualitative descriptive approach. Primary data were obtained by interview and observation. Secondary data were obtained from documents relevant agencies. Key informants numbered 2 teen boys sex workers by means of purposive sampling. The results showed that the decision to sex work through several stages including: assessing information, assess alternatives exist, consider alternatives, make commitments, and persist despite negative feedback.
\end{abstract}

Keywords: adolescent male, prostitutes, decision making

\begin{abstract}
ABSTRAK
Fenomena LSL (Lelaki berhubungan Seksual dengan Lelaki) semakin merebak, tidak lagi sebatas hubungan pribadi tetapi sudah sampai ranah komersial. Beberapa remaja laki-laki sudah memutuskan untuk menjadi Pekerja Seks Komersial. Tujuan penelitian ini adalah untuk menggambarkan proses pengambilan keputusan remaja laki-laki untuk menjadi pekerja seks komersial. Metode penelitian adalah kualitatif dengan pendekatan deskriptif. Data primer diperoleh dengan wawancara dan observasi. Data sekunder diperoleh dari dokumen instansi terkait. Informan kunci berjumlah 2 remaja laki-laki pekerja seks komersial dengan cara purposif sampling. Hasil penelitian menunjukkan bahwa pengambilan keputusan menjadi pekerja seks komersial melalui beberapa tahap diantaranya: menilai informasi, menilai alternatif-alternatif yang ada, mempertimbangkan alternatif, membuat komitmen, bertahan meskipun ada feedback negatif.
\end{abstract}

Kata kunci : remaja laki-laki, pekerja seks komersial, pengambilan keputusan 


\section{PENDAHULUAN}

Kasus prostitusi disinyalir semakin meningkat, tidak hanya dari segi kuantitas tapi juga modusnya. Prostitusi anak dan remaja merupakan modus yang belakangan ini terekspos di media massa. Seorang remaja di Surabaya berinisial NA (15 th) terciduk sebagai mucikari atau agen yang menawarkan "jasa" teman-temannya dan bahkan kakak kandungnya sendiri (Republika, 2013).

Usia remaja merupakan cikal bakal generasi produktif dalam pembangunan (Wirdhana dkk, 2013). Generasi produktif merupakan generasi yang berada pada fase menyelesaikan pendidikan, berkarir dalam pekerjaan, merencanakan berkeluarga, berpartisipasi dalam masyarakat, dan mempraktikkan hidup sehat. Berdasarkan data BPS (2013), jumlah Penduduk Kabupaten Pati tahun 2012 berjumlah 1.218.016 jiwa dengan jumlah remaja sebanyak 186.046 jiwa (15\% dari jumlah penduduk). Data ini menunjukkan remaja merupakan generasi potensial yang membutuhkan perhatian.

Sesuai

dengan

tugas perkembangan remaja akhir yang dijelaskan oleh Havighurst dalam Hurlock (1993) bahwa pada masa remaja akhir, seseorang akan mulai mempersiapkan karirnya. Oleh karena itu, pengambilan keputusan pada lakilaki yang berada pada fase remaja akhir akan semakin penting untuk menentukan karirnya. Remaja laki-laki membutuhkan lebih banyak kesempatan untuk dapat mempraktikkan dan mendiskusikan pengambilan keputusan yang realistis. Oleh karena itu, remaja laki-laki perlu diberikan lebih banyak peluang untuk terlibat dalam permainan peran dan pemecahan masalah kelompok.

Berdasarkan observasi lapangan ditemukan kasus perilaku seks bebas dan prostitusi remaja. Perilaku seks bebas dan prostitusi di kalangan remaja beresiko tinggi terhadap IMS (Infeksi Menular Seksual) dan HIV AIDS. Perilaku homoseksual gay memiliki resiko terjangkit penyakit herpes dan HIV yang lebih besar dari laki-laki yang berhubungan seksual dengan perempuan. Stenberg dan Markowits dalam Highleyman (2010) menemukan bahwa LSL (Lelaki yang berhubungan Seks dengan Lelaki) memiliki kemungkinan dua kali lebih besar dibanding laki-laki yang berhubungan seksual dengan perempuan untuk melakukan hubungan seks sebelum usia 15 tahun $(31,9 \%$ vs 17 , 3\%). Prevalensi HIV diantara LSL adalah 9,1\% dan prevalensi herpes adalah $18,4 \%$. Hal ini di kuatkan pernyataan Menteri Kesehatan Nafsiah Mboi melihat adanya tren peningkatan HIV/AIDS pada laki-laki yang bercinta dengan sesama jenis alias homo biseksual (LSL) dan laki-laki yang berisiko (LSB) atau mereka yang pergi ke tempat pelacuran. Data Integrated Biological-Behavioral Surveilance (IBBS) 2007 bahkan menuliskan peningkatan risiko HIV pada LSL sebesar 1,9\% meningkat drastis menjadi $7,4 \%$ pada 2013. Begitu pula dengan risiko HIV pada waria atau transgender yang pada tahun 2009 hanya sebesar 5,8\% menjadi $8,2 \%$ pada 2013 (Syarifah, 2014).

Berdasarkan informasi dari KDS (Kelompok Dukungan Sebaya) Rumah Matahari Kabupaten Pati, terdapat temuan 3 kasus HIV pada remaja lakilaki (20-24th) yang disebabkan oleh perilaku beresiko homoseksual gay. Jumlah remaja laki-laki pekerja seks komersial sampai saat ini tidak diketahui jumlahnya dengan pasti. Berdasarkan informasi dari informan penjangkau LSL terdapat sekitar 200 orang yang mengungkapkan identitasnya dan tergabung dalam komunitas gay, belum termasuk yang masih menyembunyikan identitas dan di luar jangkauan 
pendampingan LSL. Fenomena menarik lainnya adalah hubungan LSL ini tidak hanya sebatas hubungan pribadi akan tetapi juga sudah merambah pada komersialisasi. Hal ini menarik untuk diteliti karena lazimnya pekerja seks komersial dilakukan oleh wanita.

Tujuan penelitian untuk menggambarkan proses dan faktor-faktor yang mempengaruhi pengambilan keputusan menjadi pekerja seks komersial yang dilakukan oleh remaja laki-laki.

\section{TINJAUAN PUSTAKA}

\section{Perkembangan Remaja Laki-Laki}

Persoalan-persoalan pekerjaan lebih sentral bagi identitas remaja lakilaki dalam kehidupan sosialnya. Bagi remaja lak-laki pembentukan identitas mengawali tahap keakraban, dan masalah otonomi dan prestasi adalah persoalan yang penting menurut Gilligan (Santrock, 2007). Ekawati dan Wulandari (2011) menyatakan bahwa Perkembangan emosi dan intelektual remaja laki-laki sangat agresif dan independen, lebih objektif, menyukai pengetahuan eksakta, dan lebih mampu berpikir logis.

Menurut Piaget dalam Santrock (2002), seorang remaja termotivasi untuk memahami dunia karena perilaku adaptasi secara biologis mereka. Piaget dalam Santrock (2002) menyebutkan bahwa remaja secara aktif membangun dunia kognitif mereka dimana informasi yang didapatkan tidak langsung diterima begitu saja ke dalam skema kognitif mereka. Perkembangan kognitif remaja ini dikenal dengan tahap operasional formal. Tahap operasional formal adalah suatu tahap dimana seseorang sudah mampu berpikir secara abstrak. Seorang remaja tidak lagi terbatas pada hal-hal yang aktual melainkan pada pengalaman yang benar-benar terjadi. Dengan mencapai tahap operasional formal remaja dapat berpikir dengan fleksibel dan kompleks.

Remaja sudah mulai mempunyai pola berpikir sebagai peneliti, dimana mereka mampu membuat suatu perencanaan untuk mencapai suatu tujuan di masa depan (Santrock, 2002). Salah satu bagian perkembangan kognitif masa kanak-kanak yang belum sepenuhnya ditinggalkan oleh remaja adalah kecenderungan cara berpikir egosentrisme (Piaget dalam Papalia \& Olds, 2008). Egosentrisme yang dimaksud disini adalah "ketidakmampuan melihat suatu hal dari sudut pandang orang lain".

\section{Pengambilan Keputusan Remaja}

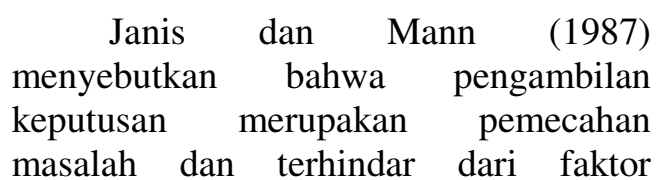
situasional. Pengambilan keputusan melibatkan beberapa tahapan. Janis dan Mann (1987) mengemukakan lima tahapan dalam mengambil keputusan, yaitu : a) menilai informasi baru, b) melihat alternatif-alternatif yang ada, c) mempertimbangkan alternatif, d) membuat komitmen, e) bertahan meskipun ada feedback negatif.

Menurut Janis dan Mann (1987) dalam mengambil keputusan individu tidak selalu melewati kelima tahapan pengambilan keputusan hal ini disebabkan adanya perbedaan proses pembelajaran dan pengalaman yang ikut mempengaruhi.

\section{Pekerja Seks Komersial}

Kartono (2009) dalam buku patologi sosial menuliskan bahwa pekerja seks komersial merupakan peristiwa penjualan diri baik perempuan maupun laki-laki dengan jalan memperjualbelikan 
badan, kehormatan dan kepribadian kepada banyak orang untuk memuaskan nafsu-nafsu seks dengan imbalan pembayaran. Hal ini didukung oleh pernyataan Mudjijono (2005), pekerja seks komersial adalah seseorang yang pekerjaan utamanya sehari-hari memuaskan nafsu seksual laki-laki atau siapa saja yang sanggup memberikan imbalan tertentu yang biasa berupa uang atau benda berharga lainnya. Menurut Fieldman dan Mac Cullah dalam Koentjoro (2004) pekerja seks komersial adalah seseorang yang menggunakan tubuhnya sebagai komoditas untuk menjual seks dalam satuan harga tertentu.

\section{METODE PENELITIAN}

Metode yang digunakan dalam penelitian ini adalah deskriptif kualitatif yaitu berupa kata-kata tertulis atau lisan dari orang-orang dan perilaku yang dapat diamati (Moleong, 2004). Fokus

penelitian ini adalah remaja laki-laki yang berada pada tahap remaja akhir. Data primer diperoleh dari wawancara dengan remaja laki-laki pekerja seks komersial, LSM penjangkau LSL, Kelompok Dukungan Sebaya HIV AIDS. Informan kunci berjumlah 2 orang. Penentuan informan dengan purposif sampling. Penelitian dilaksanakan bulan Juni-November 2014. Analisis data secara deskriptif. Analisis data yang digunakan dibagi menjadi tiga bagian yaitu reduksi data, penyajian data, dan kesimpulan.

\section{HASIL DAN PEMBAHASAN}

\section{Karakteristik Informan}

Informan kunci dalam penelitian ini adalah remaja laki-laki yang bekerja sebagai Pekerja Seks Komersial. Karakteristik informan dapat dilihat pada Tabel 1.

\section{Tabel 1.}

Karakteristik Informan Remaja Laki-Laki Pekerja Seks Komersial

\begin{tabular}{ccccccc}
\hline No. & $\begin{array}{c}\text { Nama } \\
\text { Samaran }\end{array}$ & Umur & Pendidikan & $\begin{array}{c}\text { Usia Awal } \\
\text { Menjadi PSK }\end{array}$ & $\begin{array}{c}\text { Latar belakang } \\
\text { keluarga }\end{array}$ & Anak ke \\
\hline 1 & \#Anggrek & 22 & SMA & 21 th & $\begin{array}{c}\text { Ekonomi } \\
\text { kurang }\end{array}$ & 2 dari 2saudara \\
2 & \#Pinus & 24 & $\begin{array}{c}\text { STM (sederajat } \\
\text { dengan SMA) }\end{array}$ & 22 th & $\begin{array}{c}\text { Ekonomi } \\
\text { menengah }\end{array}$ & 4 dari 4 saudara \\
\hline
\end{tabular}

Sumber :Pengolahan Data (2014)

Berdasarkan Tabel 1 diketahui bahwa informan berusia antara 22 dan 24 tahun. Namun demikian, informan mulai menjalani pekerjaan dari usia 21 \#Anggrek dan 22 tahun \# Pinus. Kedua Informan berpendidikan SMA/sederajat, dan mengakui berlatar belakang keluarga dengan ekonomi kurang mampu \#Anggrek dan menengah \#Pinus. Dalam sesi wawancara \#Anggrek menuturkan bahwa ayahnya bekerja sebagai tukang becak dan ibunya sebagai ibu rumah tangga. Kakak informan tidak bekerja karena mengalami gangguan jiwa.
Berbeda dengan Anggrek, latar belakang keluarga \#Pinus dirasakan memiliki ekonomi yang cukup. Ayah danibu \#Pinus bekerja sebagai Pedagang. Ketiga kakak \#Pinus sudah punya kehidupan yang mapan. Kedua Informan merupakan anak terakhir dalam keluarga informan.

\section{Proses Pengambilan Keputusan Menjadi Pekerja Seks Komersial}

Ada lima tahapan dalam pengambilan keputusan sesuai menurut Janis dan Mann (1987) yaitu menilai informasi, menilai alternatif-alternatif 
yang ada, mempertimbangkan alternatif, membuat komitmen, bertahan meskipun ada feedback negatif. Kelima tahapan tersebut tidak selamanya berlangsung secara optimal. Hal ini disebabkan karena adanya perbedaan proses pembelajaran dan pengalaman yang ikut mempengaruhi.

\section{Menilai Informasi Baru}

Informasi atau kejadian baru terkait dengan pekerja seks komersial yang diperoleh remaja dapat mempengaruhi prinsip yang mereka anut sebelumnya. Informasi yang diperoleh berupa cara mudah dalam mendapatkan uang. Adanya informasi yang menarik membuat individu merasa kurang nyaman karena ia menyadari adanya kesempatan dan tantangan. Informasi mengenai pekerja seks komersial pada remaja ini tidak lepas dari lingkungan remaja itu sendiri seperti teman sebaya. Hal ini dialami oleh \#Pinus dan \#Anggrek:

"Setelah lulus SMA, aku kerja di sebuah SPA di Bali, dari sana aku mulai diajak main sama teman. Diajak ke kost dan melihat aktivitas sesama. Awalnya cuma melihat saja, lama-lama diajakin, terus jadi penasaran. Mencoba pertama kali dengan teman sendiri, kalau di bayar pertama kali waktu ada pelanggan bule. Aku ditawarin teman mau diambil apa ngga?"(\#Pinus)

Berbeda dengan \#Pinus, \#Anggreak mendapatkan informasi mengenai Seks Komersial setelah bekerja di sebuah salon. Informasi tersebut didapatkan dari pemilik salon.

"Saya mengetahui dunia seperti ini setelah kerja di salon. Sudah ingin tau caranya dari dulu tapi belum punya informasi. Toh saya kan sudah berhubungan dengan pasangan dari dulu. Tapi ya suka sama suka. Tidak dibayar...paling juga dikasih-kasih dikit.
Saya dikenalkan oleh pemilik salon kepada mak-makan”(\#Anggrek)

Papalia \& Olds (2008), mengemukakan bahwa kelompok teman sebaya merupakan sumber referensi utama mengenai banyak hal terutama informasi mengenai pekerja seks komersial.

\section{Melihat Alternatif-Alternatif yang Ada}

Ketika individu yakin pada informasi yang diperolehnya maka, ia akan menentukan pilihannya dan mulai memfokuskan perhatian pada satu atau lebih pilihan. Individu akan mulai mencari informasi dari orang lain yang berhubungan dengan masalahnya (Janis dan Mann, 1987). \#Anggrek mengungkapkan :

"Aku sama pemilik salaon kan sudah seperti kakak sendiri, aku curhat tentang kondisiku. Aku butuh tambahan penghasilan untuk diriku sendiri dan keluargaku. Mau punya usaha sendiri belum mampu?"

Remaja yang mendapat informasi mengenai pekerja seks komersial akan mencari informasi lainnya, dan biasanya remaja akan mencari informasi dari teman-teman di lingkungannya. Hal ini disebabkan karena adanya kedekatan yang tinggi pada kelompok teman sebaya remaja (Paplia \& Olds, 2008).

“. . aku kan sebelumnya belum pernah tau dunia seperti itu, kan diajakin, dah liat-liat dulu kaya gimana. Aku bisa apa ndak. Prakteknya di kost salah seorang teman waktu itu. Setelah liat, aku tanya ini itu ke mereka"

Selain dari teman sebaya, remaja juga melihat media masa sebagai sumber pencarian informasi (Janis dan Mann, 1987). Hal ini seperti yang di ungkapkan oleh \#Anggrek :

"Rasa ingin tau dah lama. . semenjak masih sekolah. Tapi ga tau caranya 
gimana. Setelah punya hp, ada facebook udah deh.Ternyata gampang. Cari-cari informasinya mudah. Cari pelanggan bisa lewat facebook. kontak-kontakan dengan hp. BBM an juga”

Pemanfaatan media elektronik dilakukan oleh \#Pinus lebih kepada mencari informasi mengenai kesehatan terkait dengan aktifitas seksual yang dilakukannya.

"Aku cari-cari info di internet, agar tetap bisa terjaga kesehatanku, ndak tertular penyakit berbahaya. Tips-tipsnya seperti apa...makanya aku nggak mau kalau ada yang meminta secara anal. Aku maunya cuma sebatas oral saja. Kalau mau oke, kalau nggak ya silahkan"

\section{Mempertimbangkan Alternatif}

Setelah melihat alternatif selanjutnya individu akan memasuki tahapan ketiga yaitu mempertimbangkan alternatif. Individu akan memilih alternatif yang terbaik diantara yang tersedia baginya mulai mempertimbangkan keuntungan dan kerugian dari tiap-tiap alternatif. Terkait dengan pertimbangan pilihan yang tersedia, \#Anggrek menceritakan :

"Terus terang aku butuh uang banyak mbak. Kerja di salon saja tidak cukup. Aku punya impian untuk punya usaha sendiri, harus mengumpulkan modal, membantu orang tua. Ya. . tapi nya aku nggak mau ngomongin tentang dosa, itu urusanku ma yang di atas. Aku bisanya kayak gini. . ya udah..biarin orang bilang apa, ini hidupku sendiri. Uang-uangku sendiri. Aku kaya gini juga ndak mengganggu dia. terserahlah. .”

Setelah melakukan pertimbanganpertimbangan, individu ada yang mulai merasa yakin dan ada yang kembali raguragu dengan informasi-informasi yang telah dikumpulkannya pada tahap kedua.
Keragu-raguan ini membuat individu kembali ke tahap kedua. Hal ini dialami oleh \#Pinus :

"Pas aku punya pacar, dia perempuan, aku mencoba berhenti, tapi aku sayang sama dia. Orang tuanya pengin aku menikahinya. Tapi kan butuh biaya untuk menikah. Kedua orang tua sudah tidak ada, tak coba pekerjaan lain jadi tanaga honorer di SD, tapi penghasilannya kecil, tak sambi ngelesi juga sorenya. . juga masih kurang”

Individu akan mengumpulkan informasi lebih lanjut untuk menyakinkan dalam mengambil suatu keputusan.

\section{Membuat Komitmen}

Seseorang akan menentukan keputusan setelah ia merasa cukup yakin untuk memilih satu alternatif yang menurutnya paling baik dalam mencapai tujuan tertentu (Janis dan Mann, 1987). Remaja sebelum mengambil keputusan menjadi pekerja seks komersial, akan mempertimbangan keuntungan dan kerugian akan keputusannya. Individu yang telah yakin dengan keputusannya, akan mengambil sebuah perencanaan tindakan tertentu untuk dilaksanakan. Pengambil keputusan mulai memikirkan cara untuk mengimplementasikannya dan menyampaikan keinginannya tersebut kepada orang lain. Individu juga mempersiapkan argumen-argumen yang akan mendukung pilihannya tersebut khususnya bila ia berhadapan dengan orang-orang yang menentang keputusannya tersebut, dikarenakan pengambil keputusan menyadari bahwa cepat atau lambat orang-orang pada jaringan sosialnya yang tidak secara langsung terkena dampaknya seperti 
keluarga atau teman akan mengetahui tentang keputusan tersebut. Berbeda halnya dengan kedua informan, \#Anggrek dan \#Pinus :

"Mereka tidak ku beritahu, kalau bisa jangan sampai tahu kalau aku bekerja seperti ini, yang dia tahu aku kalau pulang bawa uang, biar dia seneng. Takutnya nanti dia jadi sedih kalau tahu”(\#Anggrek)

"Kakak tidak ada yang tau, pacar saya juga tidak saya beritahu. Masyarakat sekitar juga tidak ada yang curiga. Kalau bisa tidak usah tau mereka itu. Pernah suatu ketika kakak menemukan surat di tas, dia tidak tanya yang gimana-gimana. Mungkin dikira dari pacar saya. Kalau misalnya pergi ke jakarta, paling ditanya habis ada langganan pijet?"(\#Pinus)

Remaja yang memutuskan menjadi pekerja seks komersial biasanya hanya akan memberitahu keputusannya pada teman sebaya, biasanya pada teman yang juga sebagai pekerja seks komersial karena mereka tidak akan menentang keputusan yang telah diambil oleh remaja tersebut (Janis dan Mann, 1987).

\section{Bertahan Meskipun Ada Feedback Negatif}

Setelah mengambil sebuah keputusan, individu memasuki tahap honeymoon, dimana ia akan merasa bahagia dengan keputusannya tanpa ada rasa cemas. Remaja pekerja seks komersial merasa senang dengan keputusannya dimana mereka umumnya bahagia karena uang yang mereka peroleh dengan cara yang relatif mudah. Pandangan negatif orang lain mengenai pekerja seks komersial ataupun hal-hal yang menjadi hambatan pada keputusan remaja, tidak menjadi halangan baginya.

"Ya. . terserah kalau mau di omong orang, yang penting aku tidak mengganggu mereka. Uang-uangku sendiri. Pernah ada yang bilang 'ya Alloh. . kamu itu dulu kan pinter ngaji, kok sekarang dadi kaya gini to?', paling ya diam saja. Kalau sudah tidak tahan, namanya orang kan punya batas sabar, paling ya tak sauri begini" kenapa to lek? mbok kamu diam saja, apa aku mengganggu kamu? ndak kan?" (\#Anggrek)

Selain pandangan negatif orang, hambatan lain adalah berita mengenai resiko terkena IMS (Infeksi Menular Seksual) dan HIV AIDS yang sampai pada kedua Informan \#Anggrek dan \#Pinus :

"Awal nya dulu tidak tahu. Setelah kenal sama LSM jadi tahu. Disuruh tes darah pas ada VCT di rumah sakit Kayen juga. Misalnya sampai kena HIV ya terserah yang di atas, hidup mati itu urusan Alloh. Paling untuk mencegahnya sekarang pakai pengaman, kalau dulu ngga pernah pakai. Tapi kalau ada yang minta saja kadang-kadang nggak pakai, atau lagi pengin nggak pakai. Soalnya ga puas gitu kalau pakai pengaman terus. "(\#Anggrek)

"Ya tau kalau bisa terserang HIV atau penyakit kelamin dari internet gitu dan teman-teman juga banyak memberi tau. Makanya saya tidak pernah mau melayani kalau ada yang meminta anal. Kalau ada yang minta dilayani, biasanya aku jelaskan kesepakatan diawal, aku hanya bisa oral saja. Aku biasanya rajin control dokter mbak, kalau misalnya radang tenggorokan, akutnya mungkin ada yang tertelan pas ngoral" (\#Pinus)

Bahkan hal-hal yang berkaitan dengan keyakinan agama juga diabaikan. Seperti yang dikatakan oleh \#Anggrek dan \#Pinus :

"Ya...kalau untuk urusan dosa atau nggak, saya serahkan kepada yang di atas. Kadang berpikir kok aku jadi 
seperti ini ya? kok kaya tidak adil ya? tapi ya berusaha menerima bahwa aku saat ini, sedang menjalani kehidupanku yang sekarang, ini sudah menjadi pilihanku. Aku terus berdoa kepada Nya..moga-moga aku nanti bisa hidup lebih mapan. berumah tangga entah dengan laki-laki atau perempuan, punya usaha sendiri. . ”(\#Anggrek)

"Sebenarnya kalau bertanya balik pada hati ya...ada perasaan bersalah,kok aku seperti ini ya? meskipun aku muallaf tapi aku tahu ada hadist yang menentang perbuatankuu ini. Tapi ya...aku masih belum bisa meningggalkan. Aku masih butuh tambahan penghasilan “(\#Pinus)

Hal ini dikarenakan kesenangan yang diperoleh remaja pada saat menjalankan pekerjaannya dapat menghasilkan uang dengan cara yang relatif mudah. Kesenangan tersebut mengakibatkan remaja tetap bertahan dengan keputusannya yang diambilnya.

\section{KESIMPULAN DAN SARAN}

\section{Kesimpulan}

Pengambilan keputusan kedua informan (\#Anggrek dan \#Pinus) sebagai remaja pekerja seks komersial melalui beberapa tahapan diantaranya menilai informasi, menilai alternatif-alternatif yang ada, mempertimbangkan alternatif, membuat komitmen, bertahan meskipun ada feedback negatif. Perbedaan pengalaman yang mendasar adalah bahwa \#Anggrek sudah memiliki kecenderungan untuk menyukai sesama jenis sejak usia SD, dan menjadi Pekerja Seks Komersial adalah berdasarkan keinginannya sendiri. Hal berbeda dialami oleh \#Pinus, yang mulai mengenal dunia gay setelah lulus SMA dan menjadi pekerja seks komersial lebih dominan karena ajakan teman dan pengaruh lingkungan. Hal ini berpengaruh bahwa terhadap proses pengambilan keputusan \#Pinus yang menjadikannya ragu-ragu untuk melanjutkan sebagai PSK. Alternatif lain yang dia ambil adalah dengan mencari pekerjaan lain yang lebih mapan untuk meninggalkan PSK.

\section{Saran}

1. Institusi keluarga perlu mendapatkan penguatan, terutama keagamaan agar ia memiliki kekuatan dan bisa menjadi tempat kembali bagi anggota keluarga pada situasi apapun.

2. Lingkungan masyarakat sudah sepatutnya kembali memperkokoh fungsi kontrolnya kepada setiap individu. Paling tidak menjalankan perannya sebagai pengawal tata nilai norma yang akhirnya bisa mengarahkan perilaku dan moral masyarakat.

3. Remaja perlu dibantu untuk mendapatkan identitas diri yang sehat dan meningkatkan keterampilan

pengelolaan/pengendalian diri dan penyesuaian diri.

4. Pemerintah melalui instansi terkait dan LSM untuk memberikan akses informasi perilaku sehat. Perubahan pola pendekatan masalah dari berdasarkan gejala menjadi berdasarkan pencegahan.

\section{DAFTAR PUSTAKA}

Anonim. 2013. Usut Tuntas Kasus Siswi SMP Jadi Mucikari!. http://www. republika. co. id/berita/nasional/umum/13/06/11/ mo7bao-usut-tuntas-kasus-siswismp-jadi-mucikari, diakses 5 November 2014.

Badan Pusat Statistik Kabupaten Pati. 2013. Pati Dalam Angka Tahun 2012. Pati 
Ekawati, A. dan Wulandari, S. 2011. Perbedaan Jenis Kelamin TerhadapKemampuan Siswa Dalam Mata Pelajaran Matematika. Jurnal Socio scientia Kopertis Wilayah XI Kalimantan, Vol 3(1) : 19-24.

Hurlock, E. B. 1993. Perkembangan Remaja. Jakarta : Erlangga

Highleyman, L. 2010. Prevalensi HIV dan Herpes Antar LSL. http://www. spiritia. or. id/news/bacanews. php? nwno=2226), diakses 1 November 2014.

Janis, I. L. \& Leon Mann. 1987. Decision Making : A Psychological Analisis of Conflict, Coice, and Commitment. New York : The Free Pers.

Kartono, Kartini. 2009. Patologi Sosial. Bandung : Raja grafindo Persada.

Koentjoro. 2004. On The Spot: Tutur dari Seorang Pelacur. Yogyakarta : CV Qalams

Moleong, L. J. 2004. Metodologi Penelitian Kualitatif. Bandung : PT Remaja Rosda karya.

Mudjijono. 2005. Sarkem Reproduksi Sosial Pelacuran. Yogyakarta : Gadjah Mada University Press.
Papalia D. E. , Olds, S. W and Feldman, R. D. 2008. Human Development (Perkembangan Manusia edisi 10 buku 2). Jakarta : Salemba Humanika Santrock, J. W. 2002. Life-Span Development : Perkembangan Masa Hidup (edisi kelima). Jakarta : Erlangga. 2007. Remaja, Edisi 11, Jilid 1. Jakarta : Erlangga.

Syarifah, Fitri. 2014. Trend HIV/AIDS pada Pria Homo Meningkat, Waspadalah. http://health. liputan6. com/read/2086903/trenhivaids-pada-pria-homo-

meningkat-waspadalah, diakses 5 November 2014.

Wirdhana, I. dkk. 2013. Kurikulum Diklat Teknis Bagi Pengelola, Pendidik Sebaya dan Konselor Sebaya PIK Remaja/Mahasiswa. Badan Kependudukan dan Keluarga Berencana Nasional Provinsi Jawa Tengah.

\section{BIODATA PENULIS}

Siti Qorrotu Aini, lahir 5 Agustus 1985 di kota Pati Jawa Tengah. Sarjana (S1) Universitas Diponegoro Semarang Jurusan Psikologi Tahun 2009. Bekerja sebagai peneliti di Kantor Penelitian dan Pengembangan Kabupaten Pati. 